\title{
Erratum to: Educating Professionals for Network-Centric Organisations
}

\author{
Peter Juliff ${ }^{1}$, Tsurayuki Kado ${ }^{2}$, and Ben-Zion Barta ${ }^{3}$ \\ 1 Deakin University, Australia \\ 2 Hitachi Ltd., Japan \\ ${ }^{3}$ Bar-Code Computers Ltd., Israel
}

\section{Erratum to: \\ P. Juliff et al. (Eds.) \\ Educating Professionals for Network-Centric Organisations \\ DOI: $10.1007 / 978-0-387-35393-7$}

The book was inadvertently published with an incorrect name of the copyright holder. The name of the copyright holder for this book is: (c) IFIP International Federation for Information Processing. The book has been updated with the changes. 